06

\title{
Полимерные комплексы никеля с лигандами саленового типа как многофункциональные компоненты катодов литий-ионных аккумуляторов
}

\author{
(C) Ю.А. Положенцева, М.В. Новожилова, И.А. Чепурная, М.П. Карушев \\ Физико-технический институт им. А.Ф. Иофффе РАН, Санкт-Петербург, Россия \\ ๑ E-mail: mkarushev@mail.ioffe.ru
}

Поступило в Редакцию 3 августа 2020 г.

В окончательной редакции 23 сентября 2020 г.

Принято к публикации 9 октября 2020 г.

\begin{abstract}
Предложен метод получения двухкомпонентных композитных катодов литий-ионных аккумуляторов с активным слоем на основе литированного фосфата железа и редокс-активных проводящих полимерных комплексов никеля с основаниями Шиффа саленового типа. Исследованы структура и электрохимические характеристики полученных электродов. Показано, что в катодах, не содержащих традиционные связующие и электропроводящие углеродные добавки в составе электродного слоя, полимерные металлокомплексы не только успешно выполняют функции связующего и проводящего компонентов, но и обратимо запасают заряд, что может способствовать увеличению удельной емкости катодного слоя (по сравнению с электродами традиционного состава).
\end{abstract}

Ключевые слова: проводящий полимерный металлокомплекс, лиганд саленового типа, литий-ионный аккумулятор, композитный катод.

DOI: 10.21883/PJTF.2021.02.50544.18495

Литий-ионные аккумуляторы являются наиболее энергоемкими и широко использующимися в различных приложениях вторичными химическими источниками тока. К перспективным активным материалам катодов данных аккумуляторов относится литированный фосфат железа $\mathrm{LiFePO}_{4}$ со структурой оливина [1], имеющий ряд преимуществ перед другими катодными материалами, таких как экологическая безопасность, низкая стоимость, высокая теоретическая удельная емкость $\left(170 \mathrm{~mA} \cdot \mathrm{h} \cdot \mathrm{g}^{-1}\right)$, термическая устойчивость и отличная циклируемость [2,3]. Стандартный коммерческий катод на основе литированного фосфата железа состоит из алюминиевой подложки (токоподвода) и нанесенного на нее электродного слоя, который включает $\mathrm{LiFePO}_{4}$ в качестве активного материала, углеродную добавку (сажу), повышающую проводимость катодного слоя, и связующее (например, поливинилиденфторид (PVDF)), обеспечивающее хорошую адгезию компонентов к подложке и друг к другу. Проводящая углеродная добавка и связующее являются электрохимически неактивными компонентами электродного слоя, которые увеличивают массу катода, уменьшая при этом его удельную емкость и удельную энергию аккумулятора в целом. Сам литированный фосфат железа обладает невысокой электронной проводимостью, что приводит к необходимости нанесения на его частицы дополнительного углеродного слоя, еще более увеличивающего долю балластных веществ в электроде. В результате стандартные $\mathrm{LiFePO}_{4}$-содержащие катоды могут уступать по энергоемкости электродам на основе других активных материалов, что ограничивает их практическое применение в литий-ионных аккумуляторах.
Улучшение емкостных характеристик $\mathrm{LiFePO}_{4}$-катодов является, таким образом, актуальной задачей.

Одним из способов повысить удельную емкость катода перезаряжаемой литий-ионной батареи является замена электрохимически неактивных компонентов катодного слоя на химически инертные проводящие добавки и связующие, обладающие собственной емкостью. Высокая удельная поверхность углеродной сажи потенциально способствует протеканию побочных реакций на границе раздела электрод/электролит [4], поэтому ее замена на альтернативные материалы может также позволить существенно увеличить ресурс аккумулятора. В качестве таких материалов в ряде работ [5-7] предложено использовать органические проводящие полимеры (полианилин, полипиррол и пр.). Они характеризуются сочетанием собственной емкости, электропроводности, гибкости и эластичности, но обладают и существенными недостатками: низкой удельной емкостью и недостаточной стабильностью при гальваностатическом циклировании.

Полимерные комплексы никеля с основаниями Шиффа саленового типа poly- $\mathrm{Ni}(\mathrm{Schiff})]$ являются интересным классом полимеров, обладающих как редоксактивностью, так и собственной проводимостью. Они способны к обратимому электрохимическому окислению и восстановлению в широком диапазоне потенциалов, характеризуются высокой скоростью транспорта заряда, хорошей удельной емкостью, высокой заряд-разрядной циклируемостью и уникальной термической стабильностью [8-11]. Это позволяет рассматривать данные полимеры в качестве перспективных материалов для устройств накопления электрической энергии. В частно- 
сти, предложено использование пленок poly-[Ni(Schiff)] для модификации электродов электрохимических конденсаторов с целью увеличения их удельной емкости $[10,12]$, а также в качестве активных катодных материалов для литий-ионных аккумуляторов [13]. Наряду с хорошей стабильностью в литийсодержащих электролитах в диапазоне потенциалов $2.1-4.2 \mathrm{~V}$ (здесь и далее относительно литиевого электрода) исследованные в работе [13] полимеры продемонстрировали относительно низкую удельную емкость, что снижает их конкурентоспособность по сравнению с традиционными катодными материалами. Таким образом, целью настоящей работы является изучение возможности замены электрохимически неактивных компонентов стандартного $\mathrm{LiFePO}_{4}$-катода на полимерные комплексы никеля с саленовыми лигандами. Можно предположить, что емкость полученного электродного слоя будет являться суммой емкостей активного материала и полимера poly-[Ni(Schiff)], что позволит увеличить удельную емкость катода по сравнению с таковой для электрода стандартного состава.

Нами был разработан метод получения двухкомпонентных композитных катодов для литий-ионных аккумуляторов с активным слоем на основе коммерчески доступного порошка $\mathrm{LiFePO}_{4}$ (MTI) и полимерных комплексов никеля с лигандами саленового типа $\left(\mathrm{LiFePO}_{4} /\right.$ poly-[Ni(Schiff $\left.\left.)\right]\right)$. Структурные особенности и рабочие характеристики изготовленных композитных электродов сопоставлялись с аналогичными параметрами электродов стандартного состава.

Для синтеза полимеров использовались комплексы $[\mathrm{Ni}(\mathrm{Schiff})]$, строение которых приведено на рис. 1, $a$. Комплексы были выбраны на основании ранее опубликованных данных: полимеры на их основе продемонстрировали электрохимическую активность при потенциалах редокс-процессов в $\mathrm{LiFePO}_{4}$ (poly-[ $\left.\mathrm{Ni}\left(\mathrm{CH}_{3} \mathrm{Salen}\right)\right]-$ в диапазоне $3.1-4.2 \mathrm{~V}, \quad$ poly-[ $\left.\mathrm{Ni}\left(\mathrm{CH}_{3} \mathrm{OSalen}\right)\right]-$ в диапазоне 3.3-4.2V), высокую удельную емкость и стабильность при длительном тестировании в режиме гальваностатического заряда/разряда в литийсодержащем электролите (полимер poly-[ $\left.\mathrm{Ni}\left(\mathrm{CH}_{3} \mathrm{Salen}\right)\right]$ при этом превзошел метоксизамещенный аналог по удельной емкости, но уступил ему по устойчивости) [13]. Синтез мономеров осуществлялся по классической методике [14]. Формирование композитного слоя $\mathrm{LiFePO}_{4} /$ poly$[\mathrm{Ni}(\mathrm{Schiff})]$ проводилось методом соосаждения частиц $\mathrm{LiFePO}_{4}$ с мономером $[\mathrm{Ni}(\mathrm{Schiff})]$, способным к электроокислительной полимеризации на электроде. Процесс соосаждения осуществлялся в трехэлектродной ячейке с использованием потенциостата-гальваностата Bio-Logic (Science Instruments, Франция). Ячейка заполнялась суспензией, состоящей из частиц $\mathrm{LiFePO}_{4}\left(0.038 \mathrm{~mol} \cdot 1^{-1}\right)$, диспергированных в ацетонитрильном (AN) растворе, содержащем $0.003 \mathrm{~mol} \cdot 1^{-1}$ комплекса [Ni(Schiff)] и $0.1 \mathrm{~mol} \cdot 1^{-1}$ тетрафторобората лития $\left(\mathrm{LiBF}_{4}\right)$. Рабочим электродом служила покрытая углеродом алюминиевая фольга (MTI) площадью $1.266 \mathrm{~cm}^{2}$. Вспомогательный

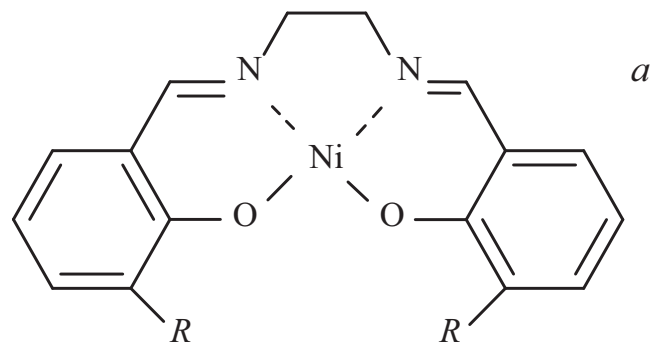

$$
\begin{aligned}
& R=\mathrm{CH}_{3}-\left[\mathrm{Ni}\left(\mathrm{CH}_{3} \mathrm{Salen}\right)\right] \\
& R=\mathrm{OCH}_{3}-\left[\mathrm{Ni}\left(\mathrm{CH}_{3} \text { OSalen }\right)\right]
\end{aligned}
$$

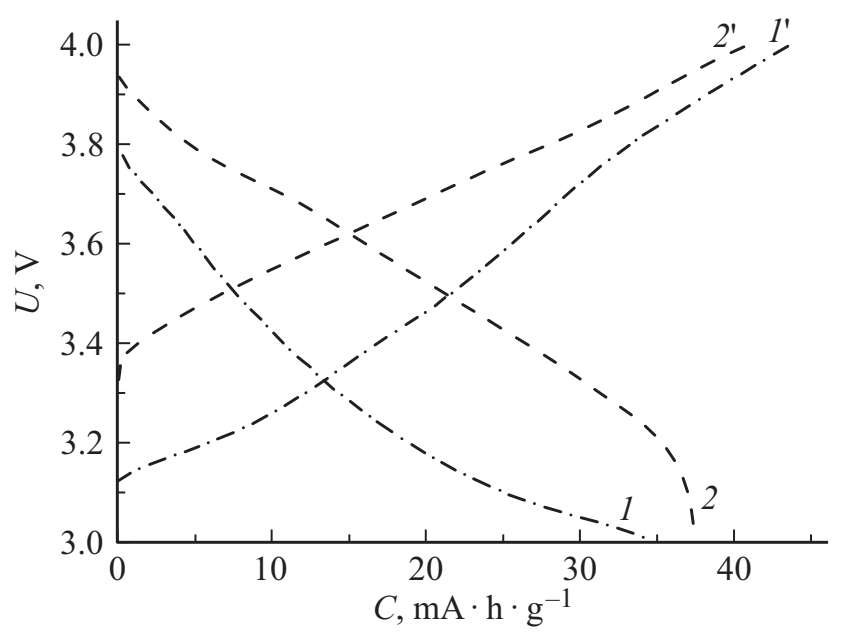

Рис. 1. $a-$ структурные формулы мономерных комплексов $[\mathrm{Ni}(\mathrm{Schiff})] . \quad b$ - кривые гальваностатического разряда $(1,2)$ и заряда $\left(1^{\prime}, 2^{\prime}\right)$ током $0.1 C$ ячеек с катодами состава poly$\left[\mathrm{Ni}\left(\mathrm{CH}_{3}\right.\right.$ Salen $\left.)\right]\left(1,1^{\prime}\right)$ и poly-[ $\left.\mathrm{Ni}\left(\mathrm{CH}_{3} \mathrm{OSalen}\right)\right]\left(2,2^{\prime}\right)$.

электрод был изготовлен из высокопористого углеродного материала с площадью, во много раз превышающей площадь рабочего электрода. В качестве электрода сравнения использовался неводный электрод MF-2062 $(\mathrm{BASi})-0.005 \mathrm{M} \mathrm{Ag}^{+} / \mathrm{Ag}$ в $0.1 \mathrm{M}\left(\mathrm{Et}_{4} \mathrm{~N}\right) \mathrm{BF}_{4} / \mathrm{AN}$ (потенциал относительно литиевого электрода $3.3 \mathrm{~V}$ ). Условия соосаждения подбирались таким образом, чтобы обеспечить эффективную полимеризацию мономерного комплекса на поверхности подложки, а также равномерное распределение и максимальное содержание частиц $\mathrm{LiFePO}_{4}$ в формирующемся двухкомпонентном композитном слое. Процесс проводился в импульсном потенциостатическом режиме (длительность импульса $4 \mathrm{~s}$, длительность паузы $20 \mathrm{~s}$ ). Во время паузы осуществлялось механическое перемешивание суспензии. Остальные условия формирования приведены в табл. 1. В результате соосаждения были получены композитные электроды в виде подложек, покрытых композитными слоями состава $\mathrm{LiFePO}_{4} /$ poly-[Ni(Schiff)]. По аналогичной методике были изготовлены монокомпонентные 
Таблица 1. Условия формирования композитных электродов $\mathrm{LiFePO}_{4} /$ poly-[Ni(Schiff)]

\begin{tabular}{c|c|c}
\hline Состав активного слоя & Потенциал импульса, $\mathrm{V}\left(\mathrm{vs} \mathrm{Li} / \mathrm{Li}^{+}\right)$ & Количество импульсов \\
\hline $\mathrm{LiFePO}_{4} /$ poly-[Ni( $\mathrm{CH}_{3}$ Salen $\left.)\right]$ & 3.9 & 30 \\
$\mathrm{LiFePO} /$ poly-[Ni( $\mathrm{CH}_{3}$ OSalen $\left.)\right]$ & 4.2 & 15
\end{tabular}

электроды, представляющие собой полимерные слои на поверхности подложек (раствор для формирования при этом не содержал частиц $\left.\mathrm{LiFePO}_{4}\right)$. Электродный слой стандартного состава наносился на покрытую углеродом алюминиевую фольгу методом ручной намазки суспензии $\mathrm{LiFePO}_{4}$, углеродной сажи марки Super P (Timcal) и PVDF (Solvay) в массовом соотношении 90:5:5 в $\mathrm{N}$-метилпирролидоне (Merck) с помощью аппликатора с регулируемым зазором (Doctor Blade, MTI). Заготовки высушивались при $120^{\circ} \mathrm{C}$, после чего электродный слой уплотнялся при помощи валков до плотности $2.5 \mathrm{~g} \cdot \mathrm{cm}^{-3}$.

Структурные особенности изготовленных электродов были исследованы методом сканирующей электронной микроскопии (СЭМ) с использованием электронного микроскопа Jeol J5M 35C. Для исследования электрохимических характеристик электроды были собраны с полипропиленовыми сепараторами (Celgard 2500) в стандартные дисковые ячейки из нержавеющей стали формата CR2032 (MTI). В качестве электролита исполь-

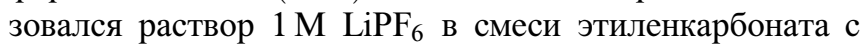
диэтилкарбонатом в массовом соотношении 1:1 (SigmaAldrich). Литиевая фольга была выбрана в качестве анода. Сборка ячеек выполнялась в перчаточном боксе в атмосфере сухого аргона. Ячейки заряжали и разряжали на стенде CT-3008W (Neware, KНP) током $0.1 C$ в диапазоне напряжений 3.0-4.0 V. Ресурсные испытания проводились при последовательном чередовании зарядаразряда ячеек токами $0.1 C$ и $1 C$.

При тестировании ячеек с монокомпонентными полимерными катодами значения удельной разрядной емкости составили $34 \mathrm{~mA} \cdot \mathrm{h} \cdot \mathrm{g}^{-1}$ для poly-[Ni( $\mathrm{CH}_{3}$ Salen $\left.)\right]$ и $37 \mathrm{~mA} \cdot \mathrm{h} \cdot \mathrm{g}^{-1}$ для poly-[ $\left.\mathrm{Ni}\left(\mathrm{CH}_{3} \mathrm{OSalen}\right)\right]$ в диапазоне 3.0-4.0 V (рис. 1,b). На кривых гальваностатического разряда ячеек со стандартными катодами состава $\mathrm{LiFePO}_{4} /$ Super P/PVDF присутствует практически горизонтальный участок (плато) при напряжении $3.38 \mathrm{~V}$ (рис. 2, $a$, кривая 3), которому соответствует плато на зарядной кривой при $3.48 \mathrm{~V}$ (рис. 2, $a$, кривая $3^{\prime}$ ). Данные участки кривых отражают процессы интеркаляции/деинтеркаляции лития [1]. Разрядная емкость ячеек при напряжениях $>3.38 \mathrm{~V}$ и их зарядная емкость при напряжения $<3.48 \mathrm{~V}$ являются практически нулевыми. Экспериментальная удельная емкость катодного слоя $\mathrm{LiFePO}_{4} /$ Super P/PVDF (табл. 2) определяется емкостью $\mathrm{LiFePO}_{4}$, составившей $154 \mathrm{~mA} \cdot \mathrm{h} \cdot \mathrm{g}^{-1}$.

На кривых разряда и заряда композитных катодов состава $\mathrm{LiFePO}_{4} /$ poly-[Ni(Schiff)] (рис. 2, $a$, кривые 1,2 и $1^{\prime}, 2^{\prime}$ соответственно) также наблюдаются харак-
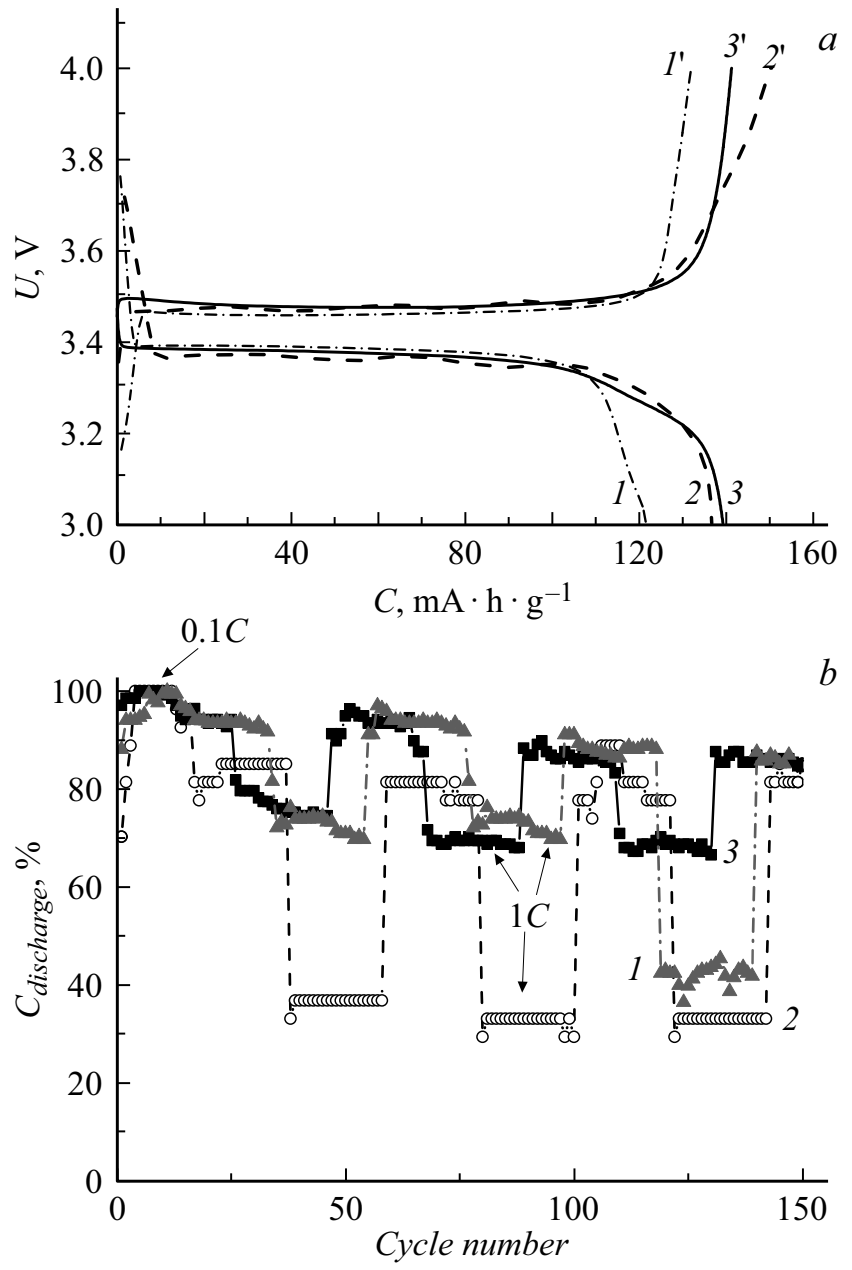

Рис. 2. $а$ - кривые гальваностатического разряда (1-3) и заряда $\left(1^{\prime}-3^{\prime}\right)$ током $0.1 C$ ячеек с катодами состава $\mathrm{LiFePO}_{4} /$ poly- $\left[\mathrm{Ni}\left(\mathrm{CH}_{3}\right.\right.$ Salen $\left.)\right] \quad\left(1,1^{\prime}\right), \quad \mathrm{LiFePO}_{4} /$ poly$\left[\mathrm{Ni}\left(\mathrm{CH}_{3} \mathrm{OSalen}\right)\right] \quad\left(2,2^{\prime}\right), \quad \mathrm{LiFePO}_{4} /$ Super P/PVDF $\left(3,3^{\prime}\right)$. $b$ - результаты циклирования ячеек с катодами состава $\mathrm{LiFePO}_{4} /$ poly-[Ni( $\mathrm{CH}_{3}$ Salen $\left.)\right] \quad(1), \quad \mathrm{LiFePO}_{4} /$ poly$\left[\mathrm{Ni}\left(\mathrm{CH}_{3} \mathrm{OSalen}\right)\right] \quad$ (2), $\mathrm{LiFePO}_{4} /$ Super P/PVDF (3) токами $0.1 C$ и $1 C$.

терные горизонтальные участки, отражающие редокспревращения в $\mathrm{LiFePO}_{4}$. Дополнительно на разрядных кривых присутствуют емкостные участки при напряжениях $>3.38 \mathrm{~V}$, а на зарядной кривой ячейки с композитным катодом $\mathrm{LiFePO}_{4} /$ poly- $\left[\mathrm{Ni}\left(\mathrm{CH}_{3} \mathrm{Salen}\right)\right]$ - выраженный емкостный участок в диапазоне $3.1-3.46 \mathrm{~V}$. Сравнение полученных данных с результатами тестирования полимерных электродов (рис. $1, b)$ указывает 
Таблица 2. Характеристики стандартного и композитных электродов на основе литированного фосфата железа

\begin{tabular}{|c|c|c|c|c|}
\hline \multirow{2}{*}{ Состав активного слоя } & \multirow{2}{*}{$\begin{array}{c}\text { Массовое соотношение } \\
\text { компонентов в активном слое }\end{array}$} & \multirow{2}{*}{$\begin{array}{c}\text { Удельная разрядная } \\
\text { емкость, } \mathrm{mA} \cdot \mathrm{h} \cdot \mathrm{g}^{-1 *}\end{array}$} & \multicolumn{2}{|c|}{ Вклад в удельную разрядную емкость, \% } \\
\hline & & & $\mathrm{LiFePO}_{4}$ & poly-[Ni(Schiff $)]$ \\
\hline $\begin{array}{c}\mathrm{LiFePO}_{4} / \text { poly- }\left[\mathrm{Ni}\left(\mathrm{CH}_{3} \text { Salen }\right)\right] \\
\mathrm{LiFePO}_{4} / \text { poly- }\left[\mathrm{Ni}\left(\mathrm{CH}_{3} \mathrm{OSalen}\right)\right] \\
\mathrm{LiFePO}_{4} / \text { Super P/PVDF }\end{array}$ & $\begin{array}{l}71: 29 \\
81: 19 \\
90: 5: 5\end{array}$ & $\begin{array}{l}121 \\
137 \\
139\end{array}$ & $\begin{array}{r}91 \\
91 \\
100\end{array}$ & $\begin{array}{l}9 \\
9 \\
-\end{array}$ \\
\hline
\end{tabular}

${ }^{*}$ В расчете на грамм активного слоя.

на то, что наклонные участки заряд-разрядных кривых электродов состава $\mathrm{LiFePO}_{4} /$ poly-[Ni(Schiff)] отражают протекание электрохимических процессов во втором компоненте катодного слоя - полимерном металлокомплексе. Емкость композитных катодов (табл. 2) является, таким образом, суммой емкостей $\mathrm{LiFePO}_{4}$ и полимера poly-[Ni(Schiff)]. Для оценки массового соотношения компонентов и их вклада в емкость электродов наклонные участки заряд-разрядных кривых электродов $\mathrm{LiFePO}_{4} /$ poly-[Ni(Schiff)] были экстраполированы с использованием заряд-разрядных кривых полимеров, а емкость $\mathrm{LiFePO}_{4}$ в композитах была принята равной емкости $\mathrm{LiFePO}_{4}$ в электродах стандартного состава $\left(154 \mathrm{~mA} \cdot \mathrm{h} \cdot \mathrm{g}^{-1}\right)$. Рассчитанные значения удельной разрядной емкости полимерных компонентов в составе электродных слоев $\mathrm{LiFePO}_{4} /$ poly$[\mathrm{Ni}(\mathrm{Schiff})]$ несколько превысили значения, полученные для полимерных электродов, и составили $38 \mathrm{~mA} \cdot \mathrm{h} \cdot \mathrm{g}^{-1}$ для poly-[Ni( $\left(\mathrm{CH}_{3}\right.$ Salen $\left.)\right]$ и $64 \mathrm{~mA} \cdot \mathrm{h} \cdot \mathrm{g}^{-1}$ для poly$\left[\mathrm{Ni}\left(\mathrm{CH}_{3} \mathrm{OSalen}\right)\right]$. Более высокие значения емкости могут отражать более высокий уровень структурирования полимерной системы в композитах по сравнению с таковым для монокомпонентных слоев. Поскольку собственная удельная емкость полимеров значительно уступает емкости $\mathrm{LiFePO}_{4}$, несмотря на достаточно высокую массовую долю полимера в композите, его вклад в суммарную емкость системы в обоих случаях относительно невысок (табл. 2).

При длительном гальваностатическом циклировании (рис. 2,b) композитные катоды продемонстрировали хорошую электрохимическую устойчивость: после 150 циклов заряда-разряда катоды состава $\mathrm{LiFePO}_{4} /$ poly-[Ni( $\left.\left.\mathrm{CH}_{3} \mathrm{OSalen}\right)\right]$ сохранили $82 \%$, а электроды $\mathrm{LiFePO}_{4} /$ poly- $\left[\mathrm{Ni}\left(\mathrm{CH}_{3}\right.\right.$ Salen $\left.)\right]$ - $88 \%$ емкости от первоначальной (при токе $0.1 C$ ), что сопоставимо с устойчивостью стандартных электродов $\mathrm{LiFePO}_{4} / \mathrm{Super}$ P/PVDF. Ячейки с электродами состава $\mathrm{LiFePO}_{4} /$ poly$\left[\mathrm{Ni}\left(\mathrm{CH}_{3}\right.\right.$ Salen $\left.)\right]$ при этом продемонстрировали сравнимую со стандартными системами способность функционировать при высоких токах заряда-разряда $(1 C)$, а также имели наиболее высокое напряжение разряда и наиболее низкое напряжение заряда из всех испытанных ячеек.

Из СЭМ-изображений поверхности электродов видно, что катодный слой $\mathrm{LiFePO}_{4} /$ Super P/PVDF (рис. 3, $a$ ) имеет неоднородную структуру с выраженными агломе-
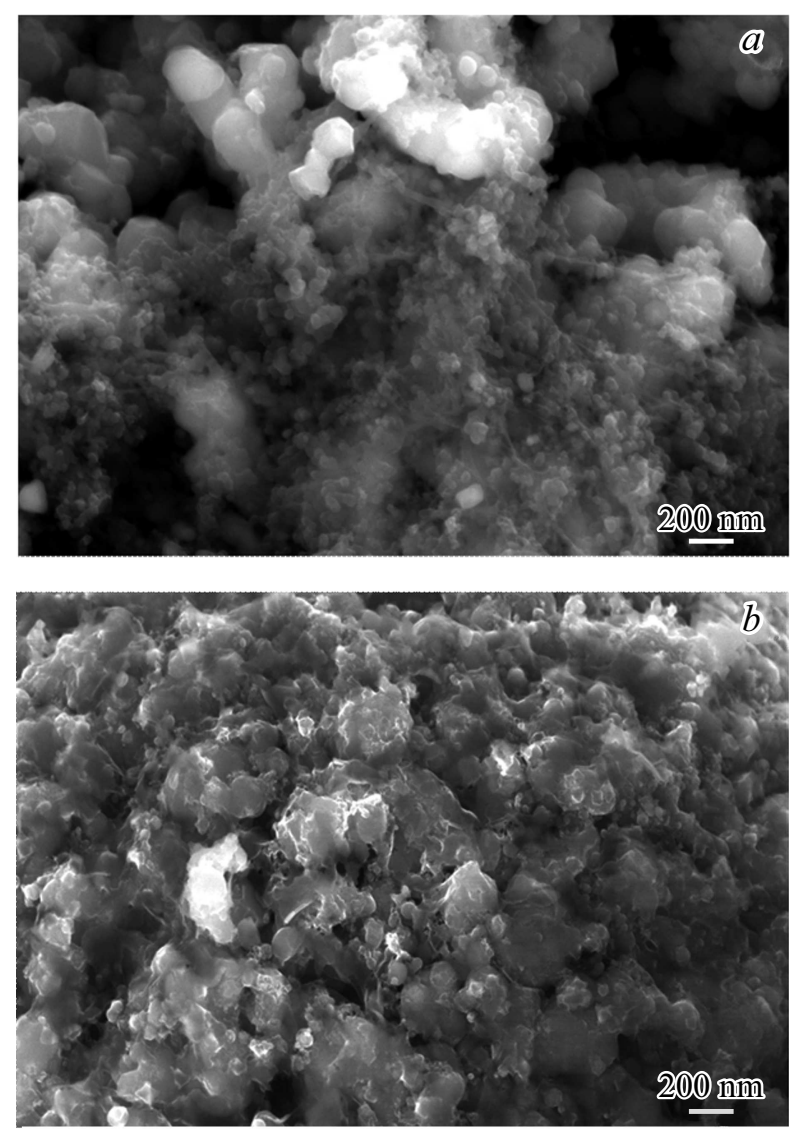

Рис. 3. СЭМ-изображения поверхности стандартного катода $\mathrm{LiFePO}_{4} /$ Super P/PVDF $(a)$ и композитного катода состава $\mathrm{LiFePO}_{4} /$ poly- $\left[\mathrm{Ni}\left(\mathrm{CH}_{3} \mathrm{Salen}\right)\right](b)$.

ратами вспомогательных компонентов на поверхности активного материала. В то же время в композитном катоде $\mathrm{LiFePO}_{4} /$ poly-[Ni( $\mathrm{CH}_{3}$ Salen)] (рис. $\left.3, b\right)$ частицы $\mathrm{LiFePO}_{4}$ равномерно покрыты полимерным металлокомплексом, создающим уникальную сетчатую матрицу, в которой обеспечивается эффективный механический и электрический контакт частиц $\mathrm{LiFePO}_{4}$ друг с другом и с материалом подложки. Такие структурные особенности композита, по всей видимости, и определяют его высокие эксплуатационные характеристики. Полученные данные можно рассматривать как предварительное свидетельство перспективности использования проводящего полимера poly-[ $\mathrm{Ni}\left(\mathrm{CH}_{3}\right.$ Salen $\left.)\right]$ вместо сажи в качестве 
электропроводящего компонента катодов на основе литированного фосфата железа.

Удельная емкость композитного катодного слоя будет выше, чем у стандартного, только при условии, что массовая доля $\mathrm{LiFePO}_{4}$ в нем будет не ниже $88 \%$ для $\mathrm{LiFePO}_{4} /$ poly- $\left[\mathrm{Ni}\left(\mathrm{CH}_{3}\right.\right.$ Salen $\left.)\right]$ или $85 \%$ для системы $\mathrm{LiFePO}_{4} /$ poly-[Ni( $\left.\left.\mathrm{CH}_{3} \mathrm{OSalen}\right)\right]$. Полученные в работе значения удельной емкости электродов соответствуют композитам, в которых массовое содержание $\mathrm{LiFePO}_{4}$ несколько ниже целевых значений (табл. 2). Вместе с тем можно ожидать, что дальнейшая доработка методики формирования электродов с активным слоем состава $\mathrm{LiFePO}_{4} /$ poly- $[\mathrm{Ni}(\mathrm{Schiff})]$ позволит снизить массовую долю полимера в них и получить более энергоемкие системы.

Таким образом, в работе показано, что метод соосаждения порошка литированного фосфата железа и полимерных комплексов никеля с лигандами саленового типа потенциально является перспективным способом получения емкостных композитных катодов для литийионных аккумуляторов. Полимерный металлокомплекс обеспечивает механический и электрический контакт частиц $\mathrm{LiFePO}_{4}$ между собой и с материалом подложки, а также выполняет энергозапасающую функцию. Предложенная методика является предварительной и нуждается в дальнейшем развитии в направлении контролируемого уменьшения содержания полимера в составе композита.

\section{Благодарности}

Исследования проведены с использованием оборудования ресурсного центра Научного парка СПбГУ „Нанотехнологии“.

\section{Конфликт интересов}

Авторы заявляют, что у них нет конфликта интересов.

\section{Список литературы}

[1] A.K. Padhi, K. Nanjundaswamy, J.B. Goodenough, J. Electrochem. Soc., 144 (4), 1188 (1997). DOI: $10.1149 / 1.1837571$

[2] A. Eftekhari, J. Power Sources, 343, 395 (2017). DOI: 10.1016/j.jpowsour.2017.01.080

[3] F. Cheng, J. Liang, Z. Tao, J. Chen, Adv. Mater., 23 (15), 1695 (2011). DOI: $10.1002 /$ adma.201003587

[4] M. Metzger, C. Marino, J. Sicklinger, D. Haering, H.A. Gasteiger, J. Electrochem. Soc., 162 (7), A1123 (2015). DOI: $10.1149 / 2.0951506$ jes

[5] T. Janoschka, C. Friebe, A. Wild, U.S. Schubert, S. Muench, B. Häupler, Chem. Rev., 116 (16), 9438 (2016). DOI: $10.1021 /$ acs.chemrev.6b00070

[6] K.S. Park, S.B. Schougaard, J.B. Goodenough, Adv. Mater., 19 (6), 848 (2007). DOI: 10.1002/adma.200600369

[7] C. Ajpi, N. Leiva, M. Vargas, A. Lundblad, G. Lindbergh, S. Cabrera, Materials, 13 (12), 2834 (2020). DOI: $10.3390 / \mathrm{ma1} 3122834$
[8] E. Dmitrieva, M. Rosenkranz, J.S. Danilova, E.A. Smirnova, M.P. Karushev, I.A. Chepurnaya, A.M. Timonov, Electrochim. Acta, 283, 1742 (2018). DOI: 10.1016/j.electacta.2018.07.131

[9] E.V. Alekseeva, I.A. Chepurnaya, V.V. Malev, A.M. Timonov, O.V. Levin, Electrochim. Acta, 225, 378 (2017). DOI: $10.1016 /$ j.electacta.2016.12.135

[10] И.А. Чепурная, С.А. Логвинов, М.П. Карушев, А.М. Тимонов, В.В. Малев, Электрохимия, 48 (5), 590 (2012).

[11] М.В. Новожилова, Е.А. Смирнова, М.П. Карушев, А.М. Тимонов, В.В. Малев, О.В. Левин, Электрохимия, 52 (12), 1324 (2016). DOI: 10.7868/S0424857016120100

[12] K. Łȩpicka, P. Pieta, G. Francius, A. Walcarius, W. Kutner, Electrochim. Acta, 315, 75 (2019). DOI: $10.1016 /$ j.electacta.2019.05.075

[13] S.N. Eliseeva, E.V. Alekseeva, A.A. Vereshchagin, A.I. Volkov, P.S. Vlasov, A.S. Konev, O.V. Levin, Macromol. Chem. Phys., 218 (24), 1700361 (2017). DOI: 10.1002/macp.201700361

[14] P. Pfeiffer, E. Breith, E. Lübbe, T. Tsumaki, Justus Liebigs Ann. Chem., 503 (1), 84 (1933). DOI: $10.1002 /$ jlac. 19335030106 